\title{
The structure of the Baikal population of Cyclops kolensis.Lill, 1901 (Copepoda, Cyclopoida) and phylogenetic relationships with some non-Baikal representatives of the species based on the molecular genetic analysis of the mtDNA C01 fragment
}

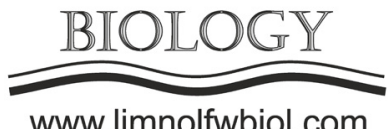

www.limnolfwbiol.com

\author{
Zaidykov I.Yu. *, Mayor T.Yu., Naumova E.Yu., Sukhanova L.V. \\ Limnological Institute, Siberian Branch of the Russian Academy of Sciences, Ulan-Batorskaya Str., 3, Irkutsk, 664033, Russia
}

\begin{abstract}
We studied the population structure of the Cyclops kolensis.Lill, 1901 copepod in Lake Baikal. For analysis, we used the fragment sequences of the cytochrome oxidase subunit 1 (CO1) of mitochondrial DNA. Based on these sequences, we constructed a haplotype tree for Baikal individuals as well as a phylogenetic tree for the sequences of Baikal and non-Baikal members of $C$. kolensis using the molecular clocks. In general, the distribution of haplotypes across the lake basins indicates the absence of geographical subdivision, although there are traces of the past local isolations as well as possible recent introductions from the water bodies near Lake Baikal. We have determined the time of the divergence between the Baikal representatives and the European ones (from the lakes of Moscow and Kiev), which dates back to 1.13 million years (95\% CI: 0.67-1.63 million years). The divergence of the Baikal group of haplotypes is 0.31 million years (CI: $0.16-0.48$ million years), which may be the time when the species entered the lake.
\end{abstract}

Keywords: Lake Baikal; CO1 mtDNA; freshwater copepods; zooplankton, cyclopoida

The species Cyclops kolensis.Lill, 1901 is widespread, occupying most of the Palearctic and the part of Nearctic. It mainly inhabits large and deep water bodies from Europe to Kamchatka and in Alaska (Mazepova, 1978; Reed, 1995; Timoshkin et al., 1995; Verbitsky et al., 2019). It can be found in small lakes and ponds in spring (Rylov, 1948; Rivier, 2012).

In Lake Baikal, C. kolensis is a constant component of plankton, although in different years it experiences abrupt fluctuations in abundance. Here, the biomass of cyclops in the upper $250 \mathrm{~m}$ layer can vary from 36 to $57 \mathrm{~g} / \mathrm{m}^{2}$ in the summer of a prolific year to hundredths of grams in the winter of a non-prolific year (Mazepova, 1978).

The population structure of the species based on the molecular genetic data has not been previously studied. The question of the time of the species introduction to Lake Baikal remains open, as well as of the existence time of the species itself, although it is considered relatively young. According to V.M. Rylov (1948), the genus began to form in the Ice Age.

Samples were collected from 2010 to 2013 using a Juday plankton net from depths of 50 to $0 \mathrm{~m}, 1 \mathrm{~km}$ from the Listvyanka settlement, in Barguzin Bay and 7 $\mathrm{km}$ from the Nizhneangarsk town as well as from depths of 5 to $0 \mathrm{~m}$ in Chivyrkuy Bay (Fig. 1). We also used single samples from the Boguchany Reservoir, Lake Telbin (Kiev) and the Andreevsky Ponds (Moscow).

For population genetic analysis, the gene fragment of the cytochrome oxidase subunit 1 (CO1) of mitochondrial DNA (mtDNA) was used. The sequences were aligned using the ClustalW software implemented in the MEGA 7.0 program (Kumar et al., 2016). This program was also used to search for the optimal evolutionary model. The saturation test of the substitutions (Xia et al., 2003) was carried out in the Dambe v.6.4. program (Xia and Lemey, 2009). Preliminary analysis of nucleotide sequences were carried out in the DNA SP v. 5 program (Librado and Rozas, 2009). The genealogy of haplotypes was assessed in the NETWORK 10 program (Bandelt et al., 1999) using a "median-joining" algorithm. The phylogenetic tree was constructed in the BEAST 1.10 program using the dates that were previously developed for the

*Corresponding author.

E-mail address: igorrock11@mail.ru (I.Yu. Zaidykov)

(C) Author(s) 2020. This work is distributed under the Creative Commons Attribution 4.0 License. 
endemic Baikal amphipod Gmelinoides fasciatus (Bukin et al., 2018).

We determined the CO1 fragment of 559 bp for 61 samples of $C$. kolensis from Lake Baikal. Several sequences were deposited in GenBank under the numbers GU055753, GU55754 and MF150246. We also obtained single sequences for the samples from the Boguchany Reservoir, Lake Telbin (Kiev) and the Andreevsky ponds (Moscow), which we also deposited in GenBank under the numbers MF150247, MF150241 and GU055749. They were used for the intraspecific phylogenetic constructions.

The saturation test of substitutions, which was carried out in the Dambe programme, indicated a low saturation level and the suitability of the sequences for phylogenetic analysis.

For Baikal sequences, we have constructed a haplotype network using the Network program (Fig. 2A). In general, the distribution of haplotypes across the lake basins indicates the absence of geographical subdivision, which, is natural for a pelagic species. The network distinguishes the central group of haplotypes, which includes 54 (of 61) sequences. Three branches extend from the central group to distal haplotypes. However, two of the three branches are geographically isolated and lead to the samples collected in the north of Lake Baikal, $7 \mathrm{~km}$ from the Nizhneangarsk town, in June 2011. To check the presence of the geographically isolated group, we again collected the C. kolensis individuals at the same site in October 2013, whose sequences were completely included in the central group of haplotypes. Based on the obtained data, we assume that the individuals that we collected in 2011 near Nizhneangarsk were brought to Lake Baikal from neighbouring water bodies where independent C. kolensis populations may also exist. A detailed phylogenetic analysis can clarify the situation with the origin of distant haplotypes as well as propose the most probable pathway of $C$. kolensis introduction to Lake Baikal. This is, first of all, an analysis of members of the species in the Angara-Baikal basin itself and the neighbouring ones.

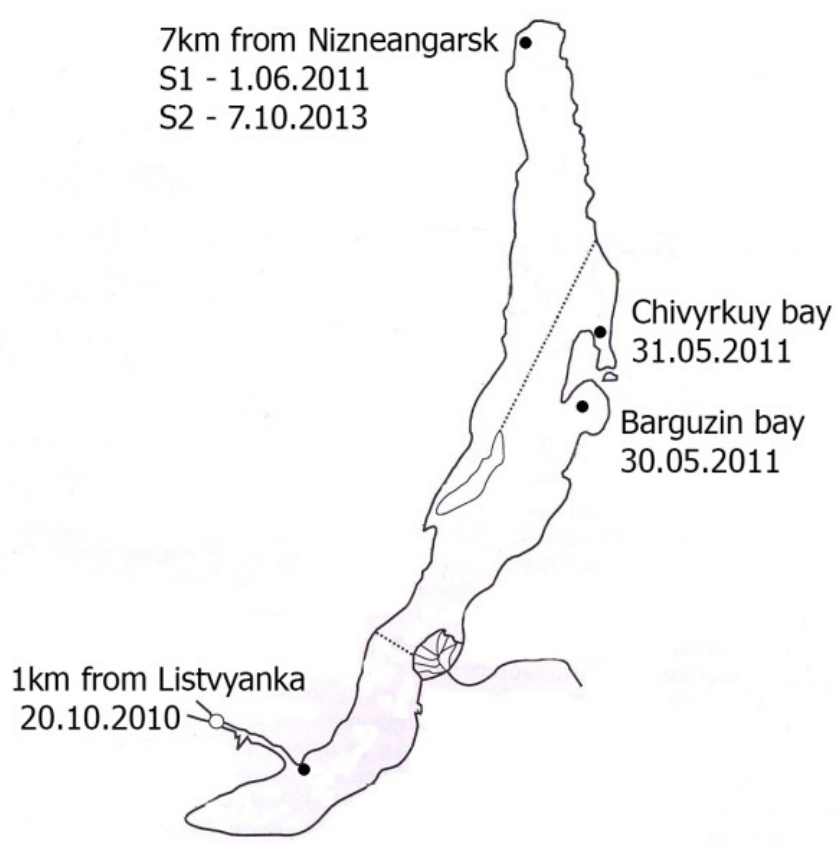

Fig.1. Sampling sites in Lake Baikal.

For Baikal and non-Baikal unique haplotypes, we constructed the phylogenetic tree in the BEAST program using the molecular clock (Fig. 2B). The sequences from Moscow and Kiev formed the common cluster; the divergence time between them and the branch leading to Baikal and near-Baikal sequences was 1.13 million years (95\% CI: 0.67-1.63 million years). One of the isolated Nizhneangarsk haplotypes (NH1) formed a cluster with the sequences from the Boguchany Reservoir, which again supports our assumption about the outside bringing. This group separated from other Baikal haplotypes 0.74 thousand years ago (95\% CI: 0.41-1.11 million years). Another geographically isolated haplotype (NH2) that we also assume to be brought outside diverged from other sequences 0.46 million years ago (95\% CI: 0.23-0.7 million years). The divergence dating of Baikal group of haplotypes is 0.31 million years (CI: $0.16-0.48$ million years). We

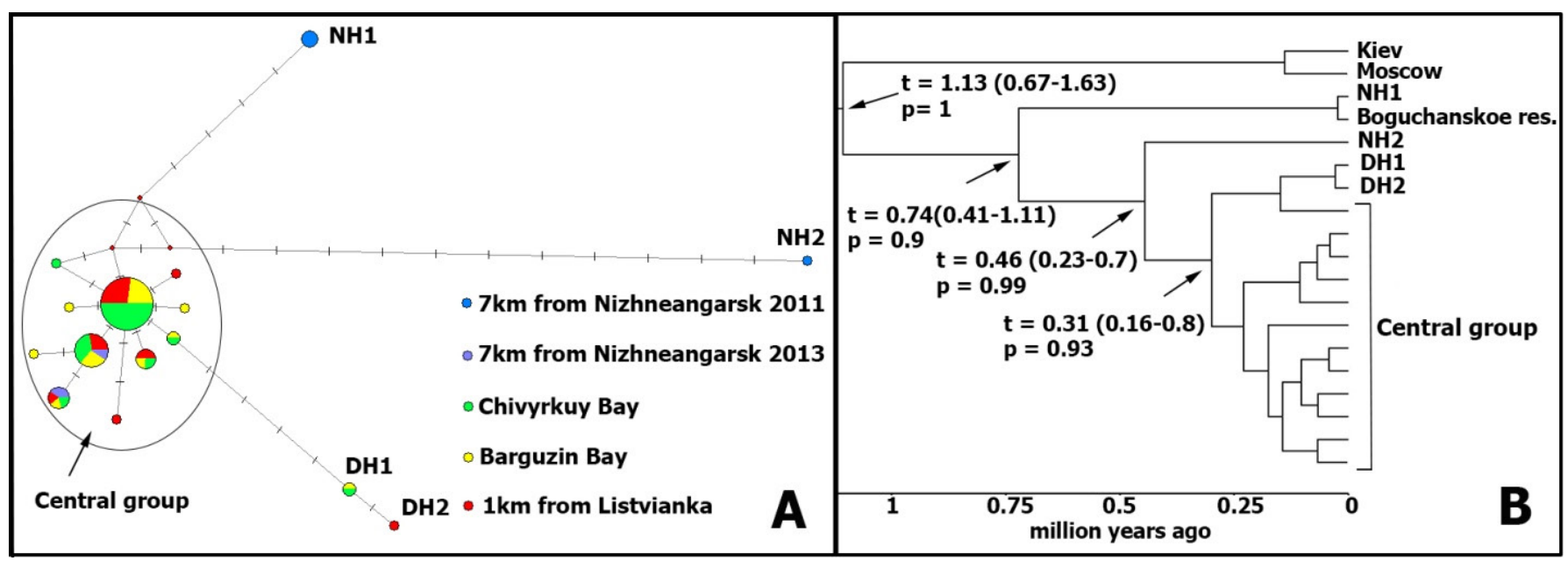

Fig.2. A. Haplotype tree constructed in the Network for Baikal sequences. Colours indicate sampling sites; NH1, NH2, DH1, and DH2 are distant haplotypes. B. Phylogenetic tree constructed for Baikal and non-Baikal haplotypes in the BEAST program using the molecular clock. There are dates of taxa divergence at the main sites; $95 \%$ confidence intervals (CI) for dating are shown in parentheses. The same sites are provided with statistical support of $\mathrm{P}$ value, a posteriori probability. 
may assume that this is the existence time of $C$. kolensis in Lake Baikal. The distant haplotypes (DH1 and DH2) can be the remnants of a once-isolated group.

This study was carried out within the framework of the State Task No. 0345-2019-0002 (AAAA-A16116122110066-1) "Molecular Ecology and Evolution of Living Systems ...” and by RFBR grant No. 19-07-00322a.

\section{References}

Bandelt H-J., Forster P., Rohl A. 1999. Medianjoining networks for inferring intraspecific phylogenies. Molecular Biology and Evolution 16: 37-48. DOI: 10.1093/ oxfordjournals.molbev.a026036

Bukin Yu.S., Petunina J.V., Sherbakov D.Yu. 2018. The mechanisms for genetic diversity of Baikal endemic amphipod Gmelinoides fasciatus: relationships between the population processes and paleoclimatic history of the lake. Russian Journal of Genetics 54: 1059-1068. DOI: 10.1134/ S1022795418090053

Kumar S., Stecher G., Tamura K. 2016. MEGA7: Molecular Evolutionary Genetics Analysis Version 7.0 for bigger datasets. Molecular Biology and Evolution 33: 18701874. DOI: $10.1093 / \mathrm{molbev} / \mathrm{msw} 054$

Librado P., Rozas J. 2009. DnaSP v5: a software for comprehensive analysis of DNA polymorphism data. Bioinformatics 25: 1451-1452. DOI: 10.1093/bioinformatics/ btp187
Mazepova G.F. 1978. Tsyklopy ozera Baikal [Cyclops of Lake Baikal]. Novosibirsk: Nauka. (in Russian)

Reed E.B. 1995. Cyclops kolensis alaskaensis Lindberg, 1956, revisited (Copepoda: Cyclopoida). Journal of Crustacean Biology 15: 365-375. DOI: 10.1163/193724095X00361

Rivier I.K. 2012. Kholodnovodnyy zooplankton ozer basseyna verkhney Volgi [Cold-water zooplankton of lakes of the upper Volga Basin]. Izhevsk: Permyakov S.A. Publishing House. (in Russian)

Rylov V.M. 1948. Cyclopoida presnykh vod [Freshwater Cyclopoida]. In: Fauna SSSR. Rakoobraznyye. Tom 3, vypusk 3 [The fauna of the USSR. Crustaceans. Vol. 3, issue 3]. Moscow- Leningrad: AN SSSR Publishing House. (in Russian)

Timoshkin O.A., Mazepova G.F., Melnik N.G. et al. 1995. Atlas i opredelitel' pelagobiontov Baikala (s kratkimi ocherkami po ikh ekologii) [Guide and key to pelagic animals of Baikal (with ecological notes)]. Novosibirsk: Nauka. (in Russian, with English contents, preface, and summary)

Verbitsky V.B., Grishanin A.K., Medyantseva E.N. et al. 2019. Thermal tolerance of Cyclops kolensis lilljeborg, 1901 (Copepoda: Cyclopoida) and its relationships with pessimal to optimal performance. Journal of Thermal Biology 86. DOI: 10.1016/j.jtherbio.2019.102429

Xia X., XieZ., Salemi M. et al. 2003. An index of substitution saturation and its application. Molecular Phylogenetics and Evolution 26(1): 1-7. DOI: 10.1016/S1055-7903(02)00326-3

Xia X., Lemey P. 2009. Assessing substitution saturation with DAMBE. The phylogenetic handbook. Cambridge: Cambridge University Press. 